\title{
Quantitative Experimental and Theoretical Research using the DFT Technique on the Structural, UV, Electronic, and FMO Properties of Gammaxene
}

\author{
Athisaya Rajah Suvitha ${ }^{1 *(\mathbb{D})}$, Nookala Yuvaraj Maharani ${ }^{(D)}$, Hrishikesh Kayarthaya Karikkad ${ }^{3(D)}$ \\ Karatholuvu Chandrasekar Varun ${ }^{4}$ iD , Ananth Steephen 5 (D) \\ Department of Physics, CMR Institute of Technology, Bengaluru, Karnataka, 560037 India \\ Department of Physics, Gopalan College of Engineering, Bengaluru, Karnataka, India \\ 3 Department of Physics, CMR Institute of Technology (VTU), Bengaluru, Karnataka, 560037 India \\ 4 Department of Physics, CMR Institute of Technology (VTU), Bengaluru, Karnataka, 560037 India \\ 5 Department of Physics, KPR Institute of Engineering and Technology (Autonomous), Coimbatore - 641 407, India \\ * Correspondence: suvidanam@gmail.com;
}

Scopus Author ID 57218331018

Received: 27.01.2021; Revised: 28.02.2021; Accepted: 2.03.2021; Published: 8.03.2021

\begin{abstract}
This investigation gives the exploratory and theoretical purpose behind the distinctive evidence of nuclear structure, expanding and bowing developments, sub-nuclear geometry, powerful UV assessment using density functional theory (DFT) system with a B3LYP/6-311++ basis set. Optical maintenance territory is ideal for fiber optic sensor applications, and the disclosures tend to describe the straightforwardness of $\gamma-\mathrm{HCH}$. Furthermore, frontier molecular orbital (FMO), UV-Visible NIR, was evaluated and seen as flawless with the exploratory characteristics. The HOMO-LUMO essentialness levels' uniqueness chooses the molecule's engine steadfastness, substance reactivity, compound nonabrasiveness, and hardness. The molecular electrostatic potential (MEP) is a critical mechanical assembly in electrophilic and nucleophilic goals affirmation. To recognize the reflection planes in the GME and to check the crystalline flawlessness of the GME, powder X-beam diffraction examples of the powdered example has been recorded utilizing a Reich Seifert diffractometer with $\mathrm{CuK} \alpha(\lambda=1.5418$ Á) radiation at $30 \mathrm{kV}, 40 \mathrm{~mA}$. In addition, ADMET boundaries, bioactivity radar, and scores are calculated using Swiss ADME and ADMET pointers to measure sub-atomic descriptors as well as to overview nuclear components.
\end{abstract}

Keywords: DFT; gammaxene; HOMO-LUMO; UV-NIR; MEP; X-ray; ADMET.

(C) 2021 by the authors. This article is an open-access article distributed under the terms and conditions of the Creative Commons Attribution (CC BY) license (https://creativecommons.org/licenses/by/4.0/).

\section{Introduction}

The $\gamma$-hexachlorocyclohexane $(\mathrm{HCH})$, officially known as benzene hexachloride (BHC), is a notable organochlorine bug sprays network. The insecticidal properties were accounted for with the gamma-isomer, which is around multiple times more noteworthy than any of the different diastereomers created in the response [1]. One of a few stereoisomers of 1,2,3,4,5,6-hexachlorocyclohexane, framed by a light-initiated expansion of benzene to chlorine. One such isomer is lindane or gammaxene bug spray [2]. The concoction expansion of chorine to benzene prompts a multi-stereoisomer blend, gammaxene (GME). GME is increasingly unpredictable and has quick, however, less continued, activity on bugs. These portrayals are urging numerous specialists to search for new incorporated photovoltaic dependent on organics[3]. Researchers then again attempt to support their biodegradation by 
altering these materials' atomic structures [4-8]. As of late, the procedure of sub-atomic reenactment has become an amazing asset for the expectation of both basic, unearthly, and thermochemical highlights through computational-based projects. For their trial FT-spectra, the creators' utilized sub-atomic reproduction as effective methods for spectroscopic confirmation [9]. Thickness utilitarian hypothesis (DFT) with the guide of Becke3-Lee-Yang - Parr (B3LYP) choosing 6-311++G (d, p) leveling superb notable style for trademark spectra estimation [10-12]. NIR-UV spectra and estimated results assist with grouping the vibrational methods of the mind-boggling pesticide atom. This way, the current examinations expect to decipher the vibrational range of the GME atom by applying density functional theory (DFT) calculations to extricate data on electronic impacts and intramolecular exchange of organic movement. Besides, ideal crystal properties, HOMO-LUMO, Total dipole moment (TDM), MEP, potential for ionization (I), electronic affinity(A), hardness( $\eta$ ),Electronic concoction potential $(\mu)$, electrophilic record $(\omega)$ and delicateness $(\zeta)$ were likewise estimated utilizing B3LYP/6-311G++(d, p) in gas, DMSO and chloroform stage. Furthermore, the counts of bioactivity and ADMET property were computed.

\section{Materials and Methods}

\subsection{Experimental details.}

The optical investigation was done utilizing Shimadzu UV-1061, NIR UV - Vis spectrophotometer of 190-1100 nm scale. Powder XRD was accounted for with $\mathrm{Cu}$ K alpha radiation utilizing Bruker D2 for the test. The investigation of an example comprises basically of deciding its structure, substance creation, imperfections, and testing its optical properties (Elwell and Scheel 1975). Gammaxene diffractometer tests were directed utilizing an X-beam diffractometer with $\mathrm{CuK} \alpha(1,5045 \mathrm{Ao})$ radiation.

\subsection{Computational details.}

Quantum chemical counts are performed utilizing DFT strategies utilizing Gauss view [13] and Gaussian09 program [14] with 6-311++G (d, p) premise sets. The DFT computations are performed utilizing the Gaussian 09 programming pack on the Pentium IV CPU, with no geometry limitation. The enhanced structure of the GME is gotten utilizing the Gauss view. Using the TD-DFT technique [15-23], the hypothetical UV-Visible range was acquired. DFT of time-subordinate thickness with a dissolvable stage (Gas, DMSO, and Chloroform) has been applied to gauge properties, such as electronic advances, oscillator speeds, HOMO-LUMO energies, MEP surface, and adjustment energies. Bioactivity and ADMET property controls have been completed using Swiss ADME amusement programming and the online ADMET marker instrument.

\section{Results and Discussion}

\subsection{Thermo-chemistry and associated physical characteristics.}

Given HOMO/LUMO energies, for instance, I=-Eномо and A= - ELumo, the ionization imperativeness (I) (the least essentialness required to knock an electron from a molecule to boundlessness) and the electron inclination (A) (the base essentialness coming out when an electron injected into a molecule outlines a negative molecule) are settled. Hardness (resistivity 
to electron cloud miss occurring or polarization in invention techniques) and substance potential (free imperativeness acclimatized or removed through a compound reaction) are moreover chosen as follows: $\eta=1 / 2$ (Elumo-Eномо), $\mu=1 / 2$ (Elumo+ EHOMO). Similarly, the electrophilic document (blessing force of the electron particles), $\omega=\mu^{2} / 2 \eta$, and nonabrasiveness (pivot hardness), $\zeta=1 / \eta$ [24]. The assessment of the connection between subnuclear orbital essentialness openings offers rise to the trading of electron-hole charges due to the excitation, change thickness, max regard, oscillator power (f), and excitation imperativeness $€$, etc. are prepared using the Gauss sum program [25]. The power form and optimized structure with molecule numbering are shown in figures 1(a) and (b).

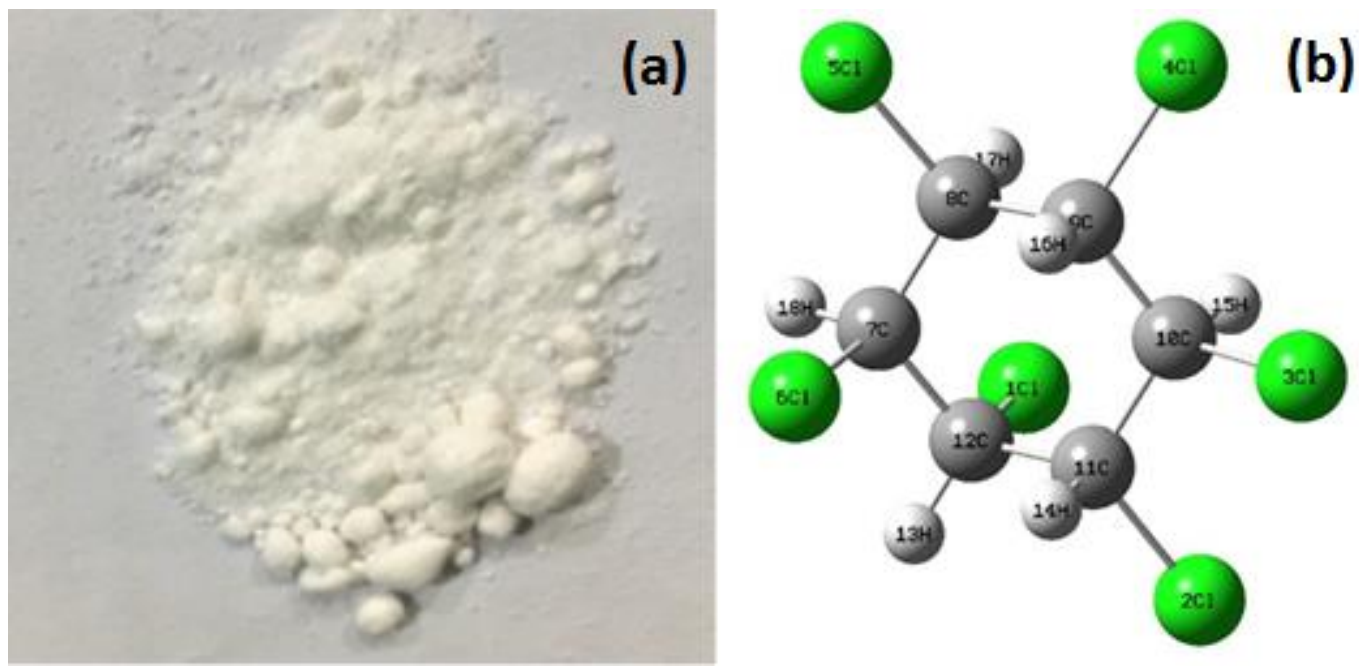

Figure 1. (a) Sample and (b) optimized structure of GME at B3LYP/6-311G (d, p).

Table 1. Thermochemistry of GME using B3LYP/6-311G (d, p).

\begin{tabular}{|c|c|}
\hline Parameters & B3LYP/6-311G(d,p) \\
\hline & Alpha MOs \\
\hline ELUMo(eV) & -1.511 \\
\hline Еномо $(\mathrm{eV})$ & -8.549 \\
\hline ELUMO+1 $_{\text {LeV) }}$ & -1.487 \\
\hline Eномо-1 $(\mathrm{eV})$ & -8.671 \\
\hline ELUMO/HOMO $(\mathrm{eV})$ & 0.177 \\
\hline Ionization energy $(\mathrm{I})(\mathrm{eV})$ & 8.549 \\
\hline Electron Affinity $(\mathrm{A})(\mathrm{eV})$ & 1.511 \\
\hline Global Hardness $(\eta)(e V)$ & 3.579 \\
\hline Chemical Potential $(\mu)(\mathrm{eV})$ & -5.03 \\
\hline Global Electrophilicity Index $(\omega)(\mathrm{eV})$ & 3.535 \\
\hline Softness $(\zeta)\left(\mathrm{eV}^{-1}\right)$ & 0.279 \\
\hline
\end{tabular}

\subsection{Frontier molecular orbital analyses.}

In the assessment of nuclear reactivity, the properties chosen for the use of HOMOLUMO are useful, particularly at the point of frequent interconnection with the natural zone [26]. The evaluation of HOMO-LUMO orbital ground (consistent) and first empowered state (higher state) was investigated in the long run by $6-311++\mathrm{G}(\mathrm{d}, \mathrm{p})$ in this study, considering different theoretical strategies for B3LYP where each technique uses the DFT approach to generate the estimate using a vaporous level. The portrayal of the HOMO-LUMO essentialness opening (Eg) using vaporous stage was showed up in figure 2. HOMO and LUMO's imperativeness qualification is generally called the essentialness gap, which offers trustworthiness to molecule structure [27]. Considering TD-DFT tallies, the Eg regards were settled as $7.038 \mathrm{eV}$ (Gas). Because of the wide bandgap among HOMO and LUMO, GME is 
used in the agricultural area as differentiated and helpful, which has been used for cultivating and non-agrarian purposes since 1949. Around $80 \%$ of hard and fast creation is used in cultivation (Demozay and Marechal, 1972), basically for seed and soil treatment [28]. Such high imperativeness opening regard, electron affinities, and high ionization potential clarify the atom's charging move instrument that impacts and non-plant (wood and timber confirmation) works out.
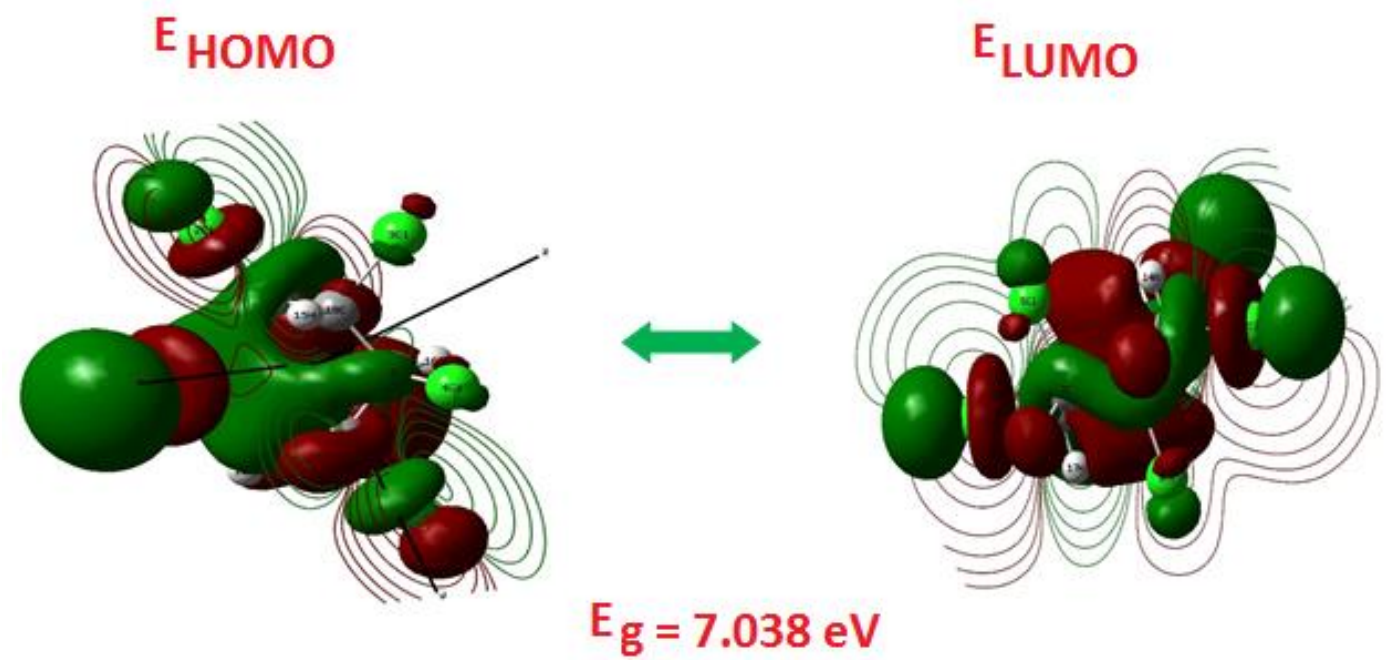

Figure 2. HOMO/LUMO offsets for GME at B3LYP/6-311G (d, p).

\subsection{UV-Vis molecular orbitals analyses.}

Hypothetical UV - Visible investigation can be acquired for every change utilizing the TD-DFT/B3LYP solvation technique [29-34] with an extraordinary 6-311G (d, p) ++ premise set. Figuring UV-Vis spectra is a major branch in the hypothetical demonstration of where Frontier evaluates elevated analytical techniques for the spectra that can be genuinely subdivided. The electronic progress for the title compound was calculated in this current analysis using the B3LYP method using 6-311++G $(\mathrm{d}, \mathrm{p})++$ base arrangement of different solvents (Gas, DMSO, and chloroform). Table 2 revealed the electronic change with the most extreme hypothetical ingestion $\lambda \max$ and their ensuing bandwidth energies. Furthermore, estimated progress vitality, oscillator power, and hypothetically got assignments were recorded in Table 2. The greatest hypothetical ingestion esteem was seen at $200 \mathrm{~nm}$ during the gas and chloroform stage utilization because of the electronic change from $\sigma$ to $\pi$, and the comparing hypothetical bandwidth vitality was noted as $6.18 \mathrm{eV}$. The greatest retention top/band hole/oscillator power utilizing DMSO solvents and relating esteem was accounted for as 199 $\mathrm{nm} / 6.21 \mathrm{eV}$. Figure 3 (a) speaks to the B3LYP/6-311++G (d, p) hypothetical figures 3 (b), (c) the experimental UV-VIS spectra, and figure 3 (d) shows the DOS graph for GME. The significant commitments of the changes are figured with the guide of the Gauss sum program [35], and the qualities are introduced in Table.2. The level of the HOMO-LUMO task esteem utilizing UV examination was $86 \%$.

\subsection{Electrostatic molecular ability.}

The 3D diagram of nuclear electrostatic potential (MEP) with a structure map for title molecule is shown in figure 4. In light of electron thickness on the atom at different centers, MEP planning is plotted. MEP is growing in the solicitation for red < orange < yellow < green $<$ blue. The MEP gives a huge idea regarding the size, shape, and particular electrostatic 
potential fields. These are imparted as concealing coding. The electronic and nuclear charge allocation of the molecule can be obtained from the MEP outline.

UV-VIS Spectrum

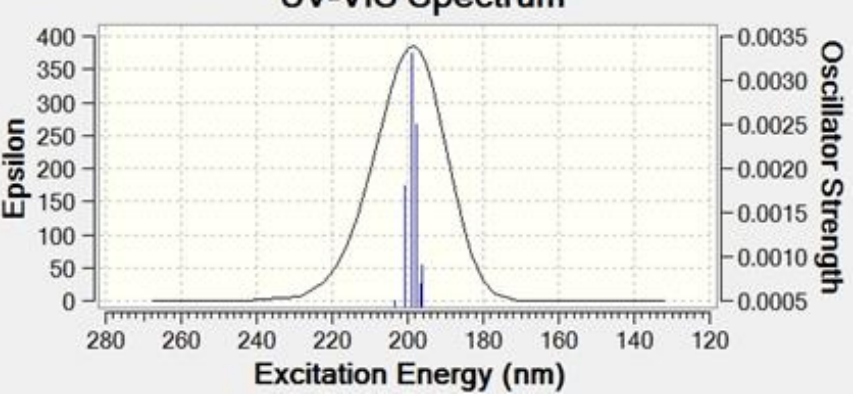

(a)

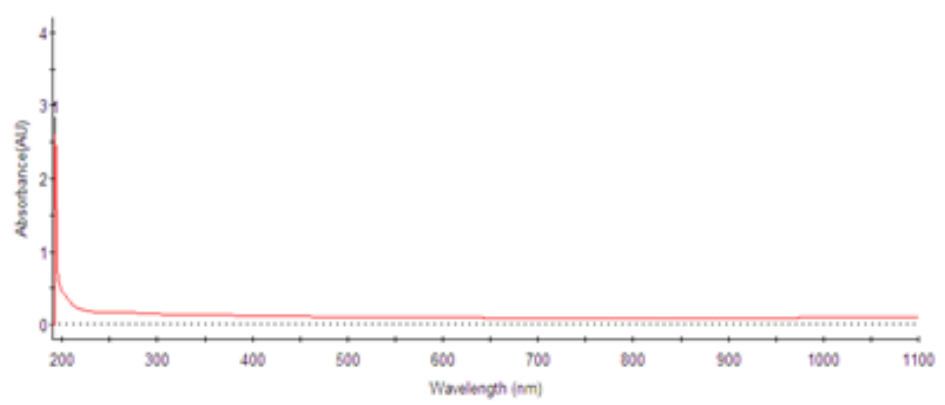

(b)
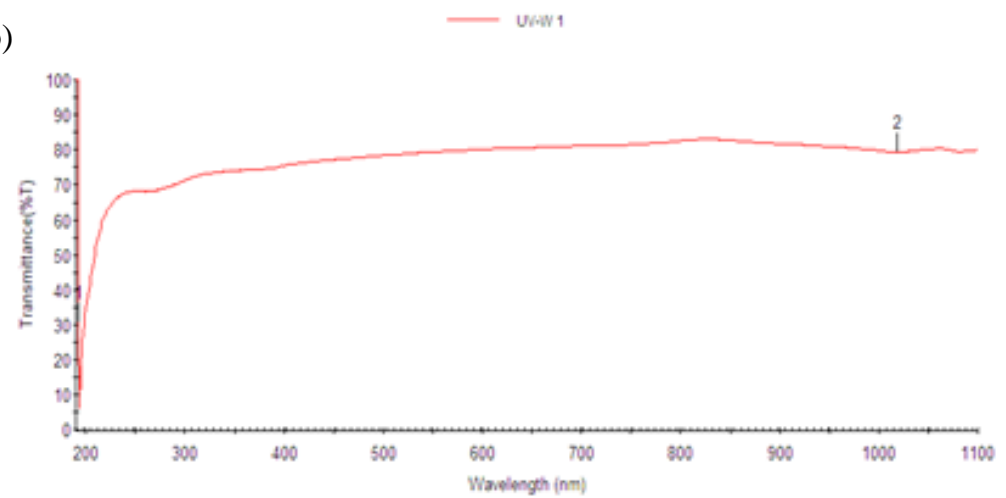

(c)
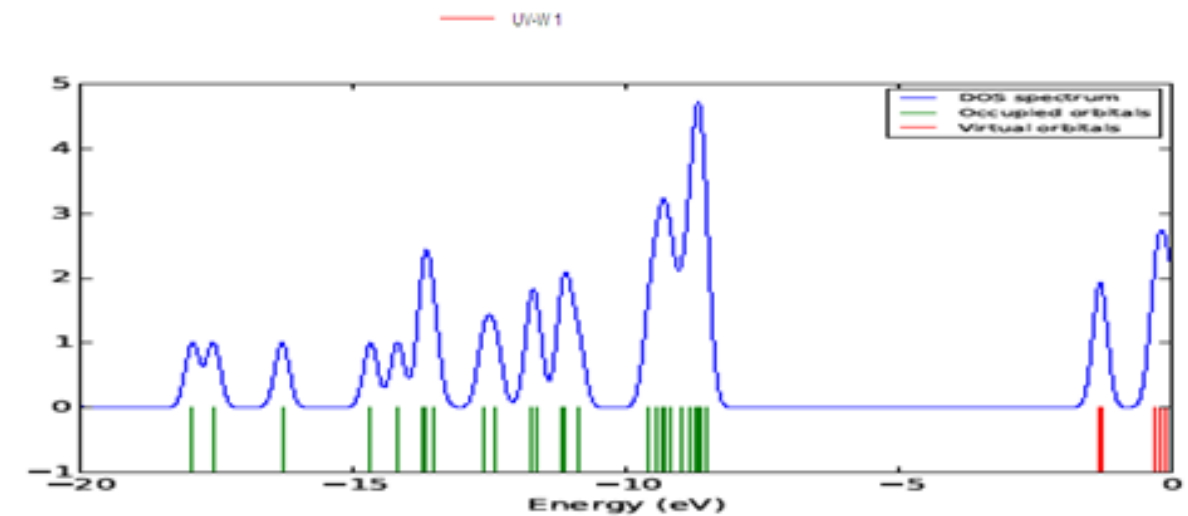

(d)

Figure 3. (a) Theoretical; (b, c) experimental UV-VIS spectra; (d) DOS chart for GME at B3LYP/6-311++ G $(\mathrm{d}, \mathrm{p})$.

Table 2. Calculated GME molecule absorption wavelength $\lambda$, excitation energies $E$, and oscillator strengths $f$ using the level B3LYP/6-311++G (d, p).

\begin{tabular}{l|l|l|l|l}
\multicolumn{1}{l|}{ Phase } & $\boldsymbol{\lambda}(\mathbf{n m})$ & $\mathbf{E}(\mathbf{e v})$ & $\boldsymbol{f}(\mathbf{a . u})$ & Major contribution \\
\hline \multirow{3}{*}{ Gas } & 200 & 6.1809 & 0.0005 & HOMO (A) $\rightarrow$ LUMO (A) (86\%) \\
\cline { 2 - 5 } & 198 & 6.2495 & 0.0026 & HOMO (A) $\rightarrow$ L+1(A) (35\%) \\
\cline { 2 - 5 } & 197 & 6.2898 & 0.0062 & HOMO-1 (A) $\rightarrow$ L (A) (80\%) \\
\cline { 2 - 5 } & 195 & 6.338 & 0.0048 & HOMO-2 (A) $\rightarrow$ L (A) (47\%)
\end{tabular}




\begin{tabular}{|c|c|c|c|c|}
\hline Phase & $\lambda(\mathrm{nm})$ & $\mathbf{E}(\mathbf{e v})$ & $f(\mathbf{a . u})$ & Major contribution \\
\hline & 194 & 6.371 & 0.0015 & $\mathrm{H}-4(\mathrm{~A}) \rightarrow \mathrm{LUMO}(\mathrm{A})(53 \%)$ \\
\hline & 194 & 6.381 & 0.0018 & H-3(A) $\rightarrow$ LUMO (A) (66\%) \\
\hline \multirow{6}{*}{ DMSO } & 199 & 6.215 & 0.0004 & HOMO (A) $\rightarrow$ LUMO (A) (78\%) \\
\hline & 197 & 6.277 & 0.0023 & $\operatorname{HOMO}(\mathrm{A}) \rightarrow \mathrm{L}+1(\mathrm{~A})(43 \%)$ \\
\hline & 196 & 6.311 & 0.0069 & HOMO-1 (A) $\rightarrow$ LUMO(A) $(73 \%)$ \\
\hline & 194 & 6.363 & 0.0061 & HOMO-2 (A) $\rightarrow$ L(A) (50\%) \\
\hline & 193 & 6.393 & 0.0019 & $\mathrm{H}-4(\mathrm{~A}) \rightarrow \mathrm{LUMO}(\mathrm{A})(55 \%)$ \\
\hline & 193 & 6.401 & 0.0012 & $\mathrm{H}-3(\mathrm{~A}) \rightarrow \mathrm{LUMO}(\mathrm{A})(76 \%)$ \\
\hline \multirow{6}{*}{ Chloroform } & 200 & 6.180 & 0.0005 & HOMO (A) $\rightarrow$ LUMO (A) (86\%) \\
\hline & 198 & 6.249 & 0.0026 & $\operatorname{HOMO}(\mathrm{A}) \rightarrow \mathrm{L}+1(\mathrm{~A})(35 \%)$ \\
\hline & 197 & 6.289 & 0.0062 & HOMO-1 (A) $\rightarrow$ L (A) (80\%) \\
\hline & 195 & 6.338 & 0.0048 & HOMO-2 (A) $\rightarrow \mathrm{L}(\mathrm{A})(47 \%)$ \\
\hline & 194 & 6.371 & 0.0015 & $\mathrm{H}-4(\mathrm{~A}) \rightarrow \mathrm{LUMO}(\mathrm{A})(53 \%)$ \\
\hline & 194 & 6.381 & 0.0018 & H-3(A) $\rightarrow$ LUMO (A) (66\%) \\
\hline
\end{tabular}

On the off chance that there ought to be an event of MEP, red concealing addresses engineered reactivity in which the best negative part or the electrophilic attack and the most outrageous positive part or the nucleophilic ambush [36] is addressed by the blue concealing. The concealing codes are addressed in the range between $-0.395 \mathrm{e}^{-2}$ (most significant red) to + $0.395 \mathrm{e}^{-2}$ (most significant blue). The potential reduces according to the solicitation blue-greenyellow-orange-red.

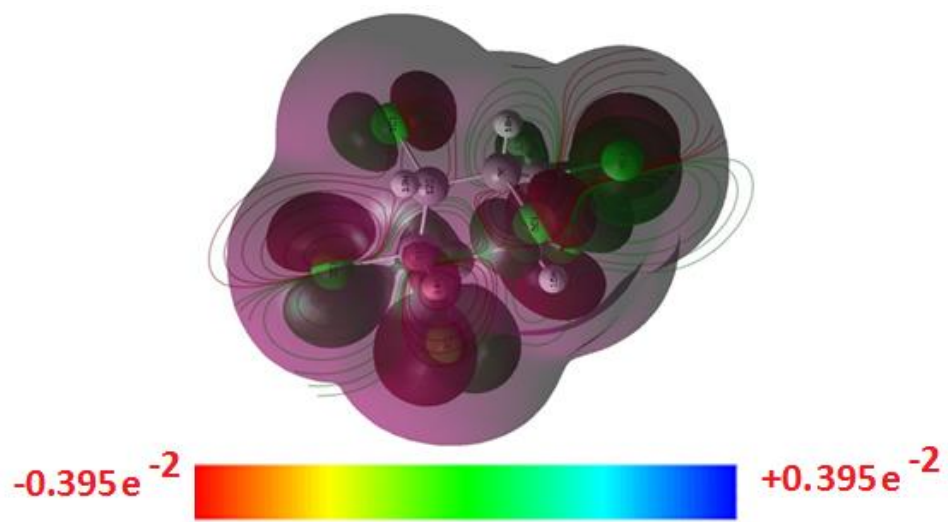

Figure 4. Molecular electrostatic potential for GME at B3LYP/6-311G (d, p).

\subsection{Powder X-Ray Diffraction Studies.}

PXRD has various favorable circumstances, in a wide scope of utilizations, for example, non-dangerous nature, high affectability, unwavering quality, profundity profiling (glancing incident angle), simple example planning, easy to use, the operational methodology is advantageous, quick speed, compelling goals, low upkeep cost, appropriate computerization, a basic understanding of knowledge that can be used. This is used to consider the crystalline structure, separate the crystalline phases, distinguish between grid planes, presence sizes, basic demand, and crystallites' epitaxial growth. Since every material has its outstanding diffraction models, it is conceivable to characterize materials and mixes using a database of diffraction designs. [37-40]. To distinguish the reflection planes in the GME and check the crystalline flawlessness of the GME, powder X-beam diffraction examples of the powdered example has 
been recorded utilizing a Reich Seifert diffractometer with $\mathrm{CuK} \alpha(\lambda=1.5418 \AA$ Á) radiation at $30 \mathrm{kV}, 40 \mathrm{~mA}$. The GME was looked over the range from $10^{\circ}$ to $80^{\circ}$ diffraction edge at an output pace of $2 \%$ minute at room temperature. The hkl planes were discovered utilizing miller indices lists. From Fig.5, the very much characterized sharp diffraction tops at explicit $2 \theta$ edges in powder XRD design show that the GME has high crystalline nature.

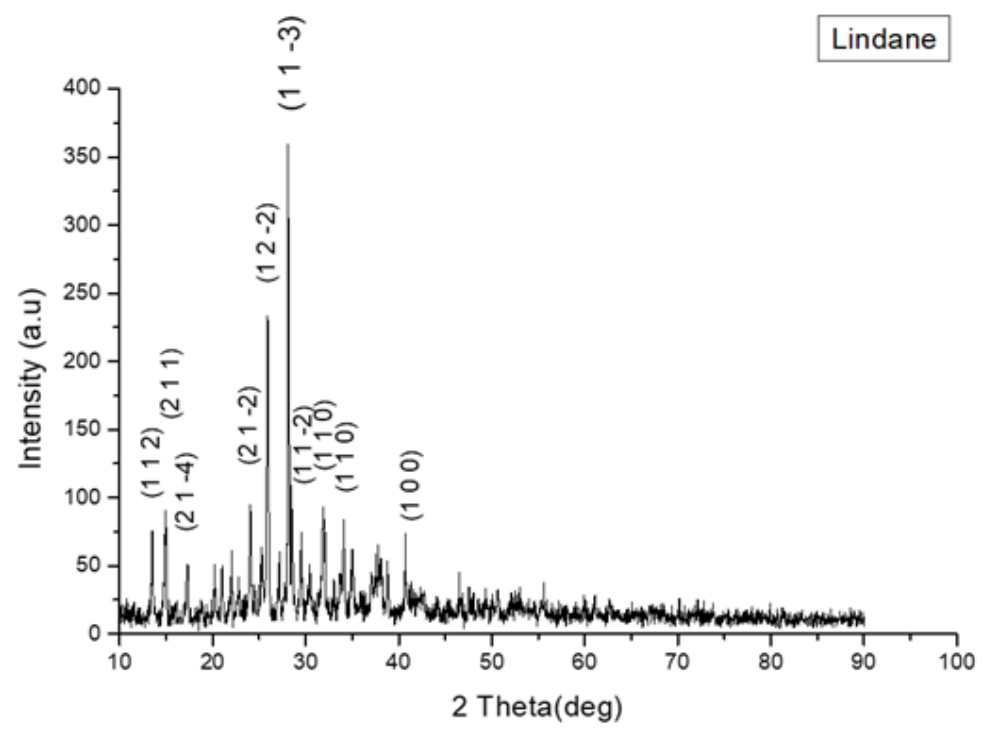

Figure 5. Sharp diffraction peaks at specific $2 \theta$ angles in powder XRD pattern for GME.

\subsection{Parameters of ADMET \& biological activity.}

ADMET Predictor is a commodity method that predicts more than 40 properties easily and accurately, including dissolvability, $\log$, CYP digestion positions, and Ames mutagenicity [41]. Six physicochemical elements, radar for bioactivity, bio score, donor, acceptors, and molar refractivity, are being measured. With a Vander Waals prediction and bioactivity radar on each axis, the molecular structure has been defined and figured in figure 6 . The pink site explains the best possible place for each venue.

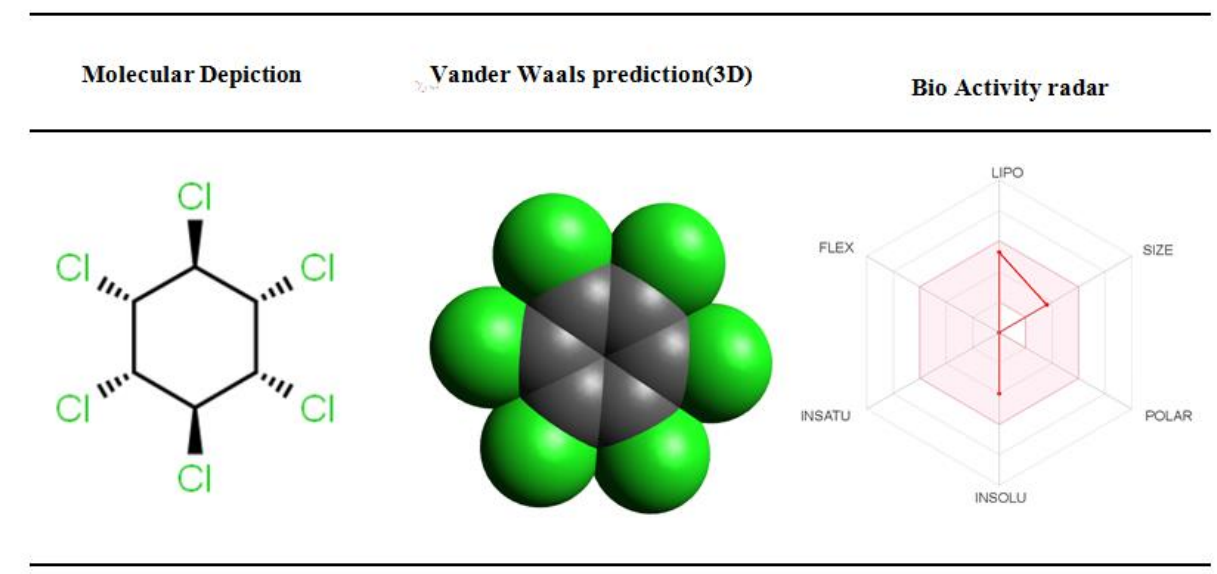

Figure 6. Vander Waals and bioactive structure for GME.

The total surface area of the selected compound is $101.38 \AA^{2}$, which indicates good intestinal absorption. Adapted descriptors have specified physicochemical calculations, are tabulated in Table 3. The pharmacokinetics/dynamics taking into account the ADMET (absorption, distribution, metabolism, excretion, and toxicity) and bio score findings in Table 4 , it has been shown that the models used to evaluate these ADMET properties are useful 
descriptors, especially with regard to crossing biological boundaries, such as access to the brain and absorption [42, 43].

Table 3. Physico-chemical calculations of studied compound

\begin{tabular}{c|c|c|c|c|c|c|c|c}
$\mathbf{L o g} \mathbf{P}$ & $\begin{array}{c}\text { Rotatable } \\
\text { bonds/Acce } \\
\text { ptor/ } \\
\text { Donor }\end{array}$ & $\begin{array}{c}\text { Number } \\
\text { of heavy } \\
\text { atoms }\end{array}$ & $\begin{array}{c}\mathbf{C s p}^{\mathbf{3}} \\
\text { Fraction }\end{array}$ & $\begin{array}{c}\text { Molar } \\
\text { Refractivity }\end{array}$ & $\begin{array}{c}\text { Total } \\
\text { surface } \\
\text { area } \\
\left(\mathbf{A}^{2}\right)\end{array}$ & $\begin{array}{c}\text { Bioavailabi } \\
\text { lity Score }\end{array}$ & $\begin{array}{c}\text { Synthetic } \\
\text { accessibility }\end{array}$ & $\begin{array}{c}\text { Van der } \\
\text { Waals } \\
\text { surface } \\
\text { area (3D) }\end{array}$ \\
\hline 3.64 & 0 & 12 & 1 & 57.62 & 101.38 & $55 \%$ & 3.68 & 230.54
\end{tabular}

Table 4. Pharmacokinetics/dynamics computations of GME.

\begin{tabular}{|c|c|c|}
\hline Property & Model Name & Predicted Value \\
\hline Absorption & Water solubility $(\log \mathrm{mol} / \mathrm{L})$ & -4.914 \\
\hline Absorption & $\begin{array}{l}\text { Caco2 permeability (log Papp in 10-6 } \\
\mathrm{cm} / \mathrm{s} \text { ) }\end{array}$ & 1.461 \\
\hline Absorption & $\begin{array}{l}\text { Intestinal absorption (human) (\% } \\
\text { Absorbed) }\end{array}$ & 90.711 \\
\hline Absorption & Skin Permeability $(\log \mathrm{Kp})$ & -1.716 \\
\hline Absorption & P-glycoprotein substrate & No \\
\hline Absorption & P-glycoprotein I inhibitor & No \\
\hline Absorption & P-glycoprotein II inhibitor & No \\
\hline Distribution & VDss (human)(log L/kg) & 0.126 \\
\hline Distribution & Fraction unbound (human)(Fu) & 0.353 \\
\hline Distribution & BBB permeability $(\log \mathrm{BB})$ & 0.694 \\
\hline Distribution & CNS permeability $(\log P s)$ & -1.864 \\
\hline Metabolism & CYP2D6 substrate & No \\
\hline Metabolism & CYP3A4 substrate & No \\
\hline Metabolism & CYP1A2 inhibitor & Yes \\
\hline Metabolism & CYP2C19 inhibitor & Yes \\
\hline Metabolism & CYP2C9 inhibitor & No \\
\hline Metabolism & CYP2D6 inhibitor & No \\
\hline Metabolism & CYP3A4 inhibitor & No \\
\hline Excretion & $\begin{array}{l}\text { Total Clearance } \\
(\log \mathrm{ml} / \mathrm{min} / \mathrm{kg})\end{array}$ & 1.053 \\
\hline Excretion & Renal OCT2 substrate & No \\
\hline Toxicity & AMES toxicity & No \\
\hline Toxicity & $\begin{array}{l}\text { Max. tolerated dose (human)(log } \\
\mathrm{mg} / \mathrm{kg} / \text { day) }\end{array}$ & 0.26 \\
\hline Toxicity & hERG I inhibitor & No \\
\hline Toxicity & hERG II inhibitor & No \\
\hline Toxicity & $\begin{array}{l}\text { Oral Rat Acute Toxicity } \\
(\mathrm{LD} 50)(\mathrm{mol} / \mathrm{kg})\end{array}$ & 2.387 \\
\hline Toxicity & $\begin{array}{l}\text { Oral Rat Chronic Toxicity (LOAEL) } \\
\text { (log mg/kg_bw/day) }\end{array}$ & 0.549 \\
\hline Toxicity & Hepatotoxicity & No \\
\hline Toxicity & Skin Sensitisation & Yes \\
\hline Toxicity & T.Pyriformis toxicity(log ug/L) & 2.521 \\
\hline Toxicity & Minnow toxicity $(\log \mathrm{mM})$ & 0.069 \\
\hline
\end{tabular}

\section{Conclusions}

The DFT-B3LYP/6-31++G (d, p) level theory is prepared to use less time to enlist the modified UV-(perceptible) helpful characteristics, HOMO, LUMO, MESP, electronic and thermo-science, and related physical properties. The relatively low opening of the HOMOLUMO essentiality band makes this biomolecule susceptible to the material reaction that can be an explanation behind a region both agrarian and non-cultivating. The GME has investigated the range from $10^{\circ}$ to $80^{\circ}$ diffraction edge at a yield pace of $2 \%$ minute at room temperature. The hkl planes were found using mill indices files records. The current assessment disclosures are derived from its uncovered activity against the scabicides and pediculicides; it has the natural development against a couple of sort's diseases. To promote drug production, the 
properties of ADMETs, bioactivity, and small molecular medicinal chemistry. These wellperforming descriptors and methods can estimate the critical activities of ADMET in optimizing pharmacokinetics and evaluating the chosen compound. Like this, the away from the title compound will be valuable for examining their answers, used in agricultural and clinical applications and blend of new materials.

\section{Funding}

This research obtained no external funding.

\section{Acknowledgments}

We would like to thank the Centre of excellence, materials science department at the CMR Institute of Technology for providing X- ray experimental facility.

\section{Conflicts of Interest}

The authors claim no conflict of interest.

\section{References}

1. Lal, R.; Pandey, G.; Sharma, P.; Kumari, K.; Malhotra, S.; Pandey, R.; Raina, V.;Kohler, H.P.E.; Holliger, C.; Jackson, C.; Oakeshott, J.G. Biochemistry of microbial degradation of hexachlorocyclohexane and prospects for bioremediation. Microbiology and molecular biology reviews, Microbiol. Mol. Biol. Rev.2010,74,1,58-80. https://doi.org/10.1128/MMBR.00029-09.

2. Kumar, D.; Pannu, R. Perspectives of lindane ( $\gamma$-hexachlorocyclohexane) biodegradation from the environment: a review. Bioresour. Bioprocess.2018, 5, 29. https://doi.org/10.1186/s40643-018-0213-9.

3. Wacławek, S.; Silvestri, D.; Hrabák, P.; Padil, VVT.; Torres-Mendieta, R.; Wacławek, M.; Černík, M.;Dionysiou, DD. Chemical oxidation and reduction of hexachlorocyclohexanes: A review. Water Res. 2019,162,302-319. https:// doi: 10.1016/j.watres.2019.06.072.

4. Anupama, K.S.; Paul, S. Ex situ and in situ biodegradation of lindane by Azotobacter chroococcum. Journal of Environmental Science and Health, Part B 2009, 45, 58-66, https://doi.org/10.1080/03601230903404465.

5. Aresta, A.; Nonnis Marzano, C.; Lopane, C.; Corriero, G.; Longo, C.; Zambonin, C.; Stabili, L. Analytical investigations on the lindane bioremediation capability of the demosponge Hymeniacidon perlevis. Mar. Pollut. Bull. 2015, 90, 143-149, https://doi.org/10.1016/j.marpolbul.2014.11.003.

6. Asemoloye, M.D.; Ahmad, R.; Jonathan, S.G. Synergistic rhizosphere degradation of $\gamma$ hexachlorocyclohexane (lindane) through the combinatorial plant-fungal action. PLoS One 2017, 12, e0183373, https://doi.org/10.1371/journal.pone.0183373.

7. Abhilash, P.C.; Srivastava, S.; Singh, N. Comparative bioremediation potential of four rhizospheric microbial species against lindane. Chemosphere 2011, 82, 56-63, https://doi.org/10.1016/j.chemosphere.2010.10.009.

8. Alexander, M. Biodegradation and bioremediation, 2nd ed.; American Chemical Society: San Diego, U.S.A, 1999, 36, 86-91.

9. Chidan Kumar, C.S.; Panicker, C.Y.; Fun, H.-K.; Mary, Y.S.; Harikumar, B.; Chandraju, S.; Quah, C.K.; Ooi, C.W. FT-IR, molecular structure, first order hyperpolarizability, HOMO and LUMO analysis, MEP and NBO analysis of 2-(4-chlorophenyl)-2-oxoethyl 3-nitrobenzoate. Spectrochimica Acta Part A: Molecular and Biomolecular Spectroscopy 2014, 126, 208-219, https://doi.org/10.1016/j.saa.2014.01.145.

10. Dereli, Ö.; Sudha, S.; Sundaraganesan, N. Molecular structure and vibrational spectra of 4phenylsemicarbazide by density functional method. J. Mol. Struct. 2011, 994, 379-386, https://doi.org/10.1016/j.molstruc.2011.03.054.

11. Kalaichelvan, S.; Sundaraganesan, N.; Dereli, O.; Sayin, U. Experimental, theoretical calculations of the vibrational spectra and conformational analysis of 2,4-di-tert-butylphenol. Spectrochimica Acta Part A: Molecular and Biomolecular Spectroscopy 2012, 85, 198-209, https://doi.org/10.1016/j.saa.2011.09.061. 
12. Abdelsalam, H.; Teleb, N.H.; Yahia, I.S.; Zahran, H.Y.; Elhaes, H.; Ibrahim, M.A. First principles study of the adsorption of hydrated heavy metals on graphene quantum dots. J. Phys. Chem. Solids 2019, 130, 32-40, https://doi.org/10.1016/j.jpcs.2019.02.014.

13. Parr, R. G; Donnelly, R. A.; Levy, M.; Palke, W. E. Electronegativity: The density functional viewpoint. $J$. Chem. Phys. 1978, 68, 3801-3807. https://doi.org/10.1063/1.436185

14. Frisch, A.; Dennington, R.; Keith, T.; Millam, J.; Nielsen, A.; Holder, A.; Hiscocks, J. Gauss view version 5 user manual, Gaussian Inc., Wallingford, CT, USA, 2009.

15. Kurban, M.;Sertbakan, T. R.; Gündüz, B. A combined experimental and DFT/TD-DFT studies on the electronic structure, structural and optical properties of quinoline derivatives. J. mol. modeling, 26, 2020,17. https://doi.org/10.1007/s00894-020-04405-5

16. John, L.; Joseyphus, R.S.; Joe, I.H. Synthesis, spectral characterization, DFT, and molecular docking studies of metal(II) complexes derived from thiophene-2-carboxaldehyde and 2-amino-6-picoline. J. Coord. Chem. 2019, 72, 2669-2687, https://doi.org/10.1080/00958972.2019.1668929.

17. Radha, V.P.; Chitra, S.; Jonekirubavathi, S.; Chung, I.-M.; Kim, S.-H.; Prabakaran, M. Transition metal complexes of novel binuclear Schiff base derived from 3,3'-diaminobenzidine: synthesis, characterization, thermal behavior, DFT, antimicrobial and molecular docking studies. J. Coord. Chem. 2020, 73, 1009-1027, https://doi.org/10.1080/00958972.2020.1752372.

18. Aggoun, D.; Messasma, Z.; Bouzerafa, B.; Berenguer, R.; Morallon, E.; Ouennoughi, Y.; Ourari, A. Synthesis, characterization and DFT investigation of new metal complexes of Ni(II), Mn(II) and VO(IV) containing N,O-donor Schiff base ligand. J. Mol. Struct. 2021, 1231, 129923, https://doi.org/10.1016/j.molstruc.2021.129923.

19. Yousef, T.A. Structural, optical, morphology characterization and DFT studies of nano sized Cu(II) complexes containing schiff base using green synthesis. J. Mol. Struct. 2020, 1215, 128180, https://doi.org/10.1016/j.molstruc.2020.128180.

20. Majumdar, D.; Das, D.; Nag, S.; Bhattacharyya, M.; Singh, D.K.; Parai, D.; Bankura, K.; Mishra, D. A rare hetero-bimetallic $\mathrm{Zn}(\mathrm{II}) / \mathrm{Ca}$ (II) Schiff base complex: Synthesis, crystal structure, DFT, molecular docking and unveiling antimicrobial activity. J. Mol. Struct. 2020, 1222, 128951, https://doi.org/10.1016/j.molstruc.2020.128951.

21. Tayo, A.D.; Djoumbissie, A.; Golngar, D.; Fomuta, T.R.; Kuate Tagne, A.C.; Anguile, J.J.; Ngoune, J.; Eleuterio, Á. Syntheses, characterization and DFT studies of two new homo-dinuclear zinc(II) complexes based on pyrazole and 3,5-dimethylpyrazole ligands. J. Coord. Chem. 2020, 73, 2055-2068, https://doi.org/10.1080/00958972.2020.1796987.

22. Saeed, A.; Khurshid, A.; Flörke, U.; Echeverría, G.A.; Piro, O.E.; Gil, D.M.; Rocha, M.; Frontera, A.; ElSeedi, H.R.; Mumtaz, A.; Erben, M.F. Intermolecular interactions in antipyrine-like derivatives 2-halo-N(1,5-dimethyl-3-oxo-2-phenyl-2,3-dihydro-1H-pyrazol-4-yl)benzamides: X-ray structure, Hirshfeld surface analysis and DFT calculations. New J. Chem. 2020, 44, 19541-19554, https://doi.org/10.1039/D0NJ03958F.

23. Maiti, M.; Thakurta, S.; Pilet, G.; Bauzá, A.; Frontera, A. Two new hydrogen-bonded supramolecular dioxomolybdenum(VI) complexes based on acetyl-hydrazone ligands: Synthesis, crystal structure and DFT studies. J. Mol. Struct. 2021, 1226, 129346, https://doi.org/10.1016/j.molstruc.2020.129346.

24. Sert, Y.; Sreenivasa, S.; Doğan, H.; Manojkumar, K.E.; Suchetan, P.A.; Ucun, F. FT-IR, Laser-Raman spectra and quantum chemical calculations of methyl 4-(trifluoromethyl)-1H-pyrrole-3-carboxylate-A DFT approach. Spectrochimica Acta Part A: Molecular and Biomolecular Spectroscopy 2014, 127, 122-130, https://doi.org/10.1016/j.saa.2014.02.069.

25. Akhtari, K.; Hassanzadeh, K.; Fakhraei, B.; Hassanzadeh, H.; Akhtari, G.; Zarei, S.A. First hyperpolarizability orientation in [70]PCBM isomers: A DFT study. Computational and Theoretical Chemistry 2014, 1038, 1-5, https://doi.org/10.1016/j.comptc.2014.03.036.

26. Raja, M.; Raj Muhamed, R.; Muthu, S.; Suresh, M. Synthesis, spectroscopic (FT-IR, FT-Raman, NMR, UVVisible), NLO, NBO, HOMO-LUMO, Fukui function and molecular docking study of (E)-1-(5-bromo-2hydroxybenzylidene) semicarbazide. J. Mol. Struct. $2017, \quad 1141, \quad 284-298$, https://doi.org/10.1016/j.molstruc.2017.03.117.

27. Zhan, C.-G.; Nichols, J.A.; Dixon, D.A. Ionization Potential, Electron Affinity, Electronegativity, Hardness, and Electron Excitation Energy: Molecular Properties from Density Functional Theory Orbital Energies. The Journal of Physical Chemistry A 2003, 107, 4184-4195, https://doi.org/10.1021/jp0225774.

28. Daina, A.; Zoete, V. Application of the Swiss Drug Design OnlineResources in Virtual Screening. Int. J. Mol. Sci. 2019, 20(18), 4612. https://doi.org/ 10.3390/ijms20184612. 
29. Sagar, S.; Parween, A.; Mandal, T.K.; Lewis, W.; Naskar, S. Mn(IV), Co(II) and Ni(II) complexes of the Schiff bases of 2-hydroxy-naphthaldehyde with amino alcohols: synthesis, characterization and electrochemical study; DFT study and Catecholase activity of Mn(IV) complex. J. Coord. Chem. 2020, 73, 2919-2940, https://doi.org/10.1080/00958972.2020.1832657.

30. Singh, Y.P.; Patel, S.K. Molecular structures, spectral, electrochemical, DFT and antioxidant activities of copper(II) complexes with NNO donor Schiff base ligand. J. Mol. Struct. 2021, 1228, 129457 , https://doi.org/10.1016/j.molstruc.2020.129457.

31. Al-Noor, T.H.; Mohapatra, R.K.; Azam, M.; Karim, L.K.A.; Mohapatra, P.K.; Ibrahim, A.A.; Parhi, P.K.; Dash, G.C.; El-ajaily, M.M.; Al-Resayes, S.I.; Raval, M.K.; Pintilie, L. Mixed-ligand complexes of ampicillin derived Schiff base ligand and Nicotinamide: Synthesis, physico-chemical studies, DFT calculation, antibacterial study and molecular docking analysis. J. Mol. Struct. 2021, 1229, 129832, https://doi.org/10.1016/j.molstruc.2020.129832.

32. Kansız, S.; Qadir, A.M.; Dege, N.; Faizi, S.H. Two new copper (II) carboxylate complexes based on N,N,N',N'-tetramethylethyleneamine: Synthesis, crystal structures, spectral properties, dft studies and hirshfeld surface analysis. J. Mol. Struct. $2021, \quad$ 1230, 129916 , https://doi.org/10.1016/j.molstruc.2021.129916.

33. Panigrahi, D.; Subramaniyan, V.; Mani, G. Synthesis and structural characterizations of Pd(II) complexes bearing the new hexahydropyrimidine and tetrahydropyrimidinium based bis(pyrazole) ligands with DFT studies. J. Mol. Struct. 2021, 1231, 129949, https://doi.org/10.1016/j.molstruc.2021.129949.

34. Oueslati, Y.; Kansız, S.; Valkonen, A.; Sahbani, T.; Dege, N.; Smirani, W. Synthesis, crystal structure, DFT calculations, Hirshfeld surface, vibrational and optical properties of a novel hybrid non-centrosymmetric material (C10H15N2)2H2P2O7. J. Mol. Struct. 2019, https://doi.org/10.1016/j.molstruc.2019.06.110.

35. Berndt, Bruce C.; Evans, Ronald J.; Williams, Kenneth S. Gauss and Jacobi Sums. Wiley and Sons.1998, ISBN 0-471-12807-4.

36. Hakiri, R.; Ameur, I.; Abid, S.; Derbel, N. Synthesis, X-ray structural, Hirshfeld surface analysis, FTIR, MEP and NBO analysis using DFT study of a 4-chlorobenzylammonium nitrate (C7ClH9N)+(NO3)-. J. Mol. Struct. 2018, 1164, 486-492, https://doi.org/10.1016/j.molstruc.2018.03.068.

37. Chauhan, A.; Chauhan, P. Powder XRD Technique and its Applications in Science and Technology, J. Anal. Bioanal Tech. 2014, 5, 212, https://doi.org/10.4172/2155-9872.1000212.

38. Liss, K.-D.; Bartels, A.; Schreyer, A.; Clemens, H. High-Energy X-Rays: A tool for Advanced Bulk Investigations in Materials Science and Physics. Textures and Microstructures 2003, 35, 587859, https://doi.org/10.1080/07303300310001634952.

39. Skakle, J. Applications of X-ray powder diffraction in materials chemistry. Chem. Rec. 2005, 5, 252-262, https://doi.org/10.1002/tcr.20050.

40. Bearden, J.A. X-Ray Wavelengths. Rev. Mod. Phys. 1967, 39, 78-124, https://doi.org/10.1103/RevModPhys.39.78.

41. Daina, A.; Michielin, O.; Zoete, V. iLOGP: a simple, robust, and efficient description of n-octanol/water partition coefficient for drug design using the GB/SA approach. J. chem. Infor. and modeling, 54(12),2014, 3284-3301. https://doi.org/10.1021/ci500467k.

42. Douglas E. V. Pires; Tom L. Blundell; David B. Ascher, pkCSM: Predicting Small-Molecule Pharmacokinetic and Toxicity Properties Using Graph-Based Signatures, J. Med. Chem. 2015, 14;58(9), 4066-72 https://doi.org/10.1021/acs.jmedchem.5b00104.

43. Du, Q.; Mezey, P.G.; Chou, K.-C. Heuristic molecular lipophilicity potential (HMLP): A 2D-QSAR study to LADH of molecular family pyrazole and derivatives. J. Comput. Chem. 2005, 26, 461-470, https://doi.org/10.1002/jcc.20174. 